resulted from the cannonade. Mr. Blacklock (Madras, 1848) anys: "I hope yet to see the day when sulphur, in small quantities, will be regularly issued to every soldier in the field, in India, say forty grains per day, while actually marching, and trenty grains per day, during halts, as a sure way of warding off this terrible disease; and I have a firm belief that sulphur, so employed, will be as effectual in banishing cholera from our armies, as lime-juice has been in eradicating scurvy from our fleets."

Mr. Grove quotes the following curious passage from the London Practice of Physic-a work published in 1692:"In the year 1670, about the autumnal equinox, a world of people here were seized with a most dangerous tlux (though without blood), and joined with a cruel vomiting, which presently caused great faintings and a total decay of ftrength. For the cure of this disease, no evacuation did good; nay, bleeding, vomiting, and purging did hurt : only cordials, and those of the hottest nature, to wit, such as abounded with spirit and sulphur, did good." (p. 22.) From this, it would appear that the whiskey and sulphur treatment of the south muirs of Scotland is an old tradition.

Manec administered sulphur in all possible forms, in his treatment of Cholera in the Salpêtrière in 1849 .

Sulphur is a stimulant of the capillary circulation, and so is camphor-one of our best remedies against collapse. Perhaps the combination of the sulphur with hydrogen is the cause of the augmented heat in the surface of those who take the former in repeated doses. The characteristically offensive smell of sulphuretted hydrogen gas is sufficient proof that this chemical action does take place. The therapeutic action of sulphur is, however, yet open to investigation.

The treatment of cholera cannot be reduced to any routine formulary, but ought to be adapted to the particular condition of each patient in each stage of the disease.

The principal indications of treatment may be thus summed up :

1. The "rice-water" romit and purging require to be energetically subdued by quinine, sulphuric and other acids, creasote, nitrate of silver, and such like remedies.

2. In actual and threatened collapse, external warmth, stimulant embrocations, and those internal stimulants which act on the capillaries, are of signal benefit.

3. In reaction, and during convalescence, local inflammations and congestions reyuire to be guarded against or subdued; and rational means must be adopted to restore the secretions of the liver, kidneys, and skin, but particularly of the two former.

4. Lastly, though not of less importance, the character cf the fever should be moditied, and a repetition of the paroxysm guarded against, by change of air, or by the administration of quinine, which, in the majority of cases, from the existence of anæmia, ought to be conjoined with iron.

Putney, I ondon, November 5, 1×53.

\section{REPORT OF THE READING PATHOLOGICAL SOCIETY.}

By W. W. MOXHAY, Esq.

[Read June 'stth, 1853.]

The annual retrospective address of the Reading Pathological Society contains many cases of interest; and will serve to shew how great an amount of information may be derived from attendance on such meetings. The cases are arranged under the heads of the various systems diseased.

DIBEARES OF THE NERVOUS SYSTEM.

Softening of the Spinal Cord : Death. By T. L. Wair PORD, Esq. (June 30th, 1852). Mr. Walford mentioned the case of Edward Gore, aged 51, who got wet on the 9th October 1852, and lay asleep for some time in an outhouse in his wet clothes. On the 11th, on rising to go to work, he found great difficulty in moving his legs. On the 12th, his arms also became reak, and he became restless, constantly requesting to be lifted out of bed, etc. On the stantly requesting to be lifted out of bed, etc. Ondistinct; his breathing also became difficult and gasping; his voice dwindled to a whisper; and he expired on the 21st.

Examination of the Body. The spinal marrom was found softened in parts, in some being quite diffluent, and there was much fluid in the theca vertebralis. This case seemed very similar to that of the late Mr. Dunn. He was exposed to cold; numbness and loss of power in the feet began soon after, with the addition of pain along the sciatic nerves, and in the sacrum. The paralysis gradually crept upwards, and ultimately killed him by suffocation, from the intercostal and phrenic nerves being implicated. A post mortem examination would doubtless have revealed a similar state of things to that found in Mr. Walford's case.

Tetanoid Disease. By F. A. Bulley, Esq. (Nov. 24th, 1852.) George Chilvers, aged 19, applied at Mr. Bulley's house on the evening of April 26th, with painful tonic contraction of the forefinger and thumb of the left hand, the result of a wound which he had received four days previously. He was told by a fellow-servant that he might have locked-jaw; and soon afterwards, in gaping, his mouth became fixed in the open position, and he could not shut it again for five minutes. Tobacco steeped in brandy was applicd, and the muscles relaxed. Soon afterwards, the boy took hold of a broom, and the hand became so firmly clenched on the handle, that he could not let it go for some time. He seemed to have been much frightened by something a druggist practising in the town said to him, and applied in consequence at Mr. Bulley's surgery. Mr. Bulley found a slight cut between the thumb and forefinger nearly cicatrised. The countenance expressed alarm; the pulsc was quick, but feeble; and the skin pale and cold. The chief complaint, on the patient's part, was that the jaw, finger, and thumb, were very stiff. Mr. Bulley was about to pass a few mild shocks of electro-galvanism from the brachial plexus downwards, and had just adjusted the poles of a battery for that purpose, when the boy swooned. On his recovery from this state, muscular twitchings took place in the body and limbs, and the whole became convulsed, the trunk being violently bent backwards as in opisthotomos, so that three men were required to hold him. Some froth oozed from his mouth. The convulsions recurred frequently, and the boy seemed partially insensible in the intervals. He spoke little, and with difficulty. The skin remained cold and bathed in cold perspiration, and the pulse very feeble. The muscular disturbance began to diminish in about four hours, when, a conversation being held in the patient's hearing about procuring a shutter, and the necessity of conveying him on it to the hospital, it ceased altogether, and he was removed in a state of fatigue to that institution. He subsequently complained of some pain up the arm, and the finger and thumb remained contracted into the palm of the hand for some days. He had, however, no further convulsions, and was soon discharged well.

Disease resembling Hydrophobia. By F. A. Bulley, Esy. (Nov. 24th, 1852.) Mr. Bulley was called on the 2nd September, 1851, at 8 P.M., to James Woodlands, aged 28 , a man of intensely melancholy countenance. He found him laid on some bedding in a yard in Friar Street, with several people holding him, whilst his body and limbs were affected with violent contortions. These had been going on for some time, and recurred every five or ten minutes. In the intervals, he was moody, frequently sighed, and was obstinately silent. The jaws were firmly closed, except when a teaspoon or cup containing fluid was brought near him. He in this case made attempts to bite at the article, and his countenance became expressive of great horror; he would utter a low groan, his features relaxed from their malignant expression, muscular contractions ensued, beginning in the face and extending over the whole body, which, at length, was thrown into convulsions, so violent 
a to require four or fire men to prevent injury. Mr. Bulley, thinking the case one of epileptic seizure, ordered water to be brought, for the purpose of dashing some on his face. A little made a splash on the stones; intense horror Was shown by the man; he endesvoured to rise, and snapped at Mr. Bulley like a dog, and the convulsions became more violent. These ceased about half-past one A.M., when the hospital was mentioned, and the patient firmly ordered to get np. He walked with assistance. Mr. Bulley mentioned, that, upon turning on a water-tap which was in the court, the greatest horror was shown by the man; and even spitting on the ground near hin produced a similar result, and excited a convulsion. He stated the extreme resemblance of this case to one of hydrophobia he had seen in London; and how much alarmed he was on this account for the result, especially as there were some wounds on the patient's hand, of which no history could be obtained. After the removal to the hospital, no further symptoms were noticed, except the moodiness of countenauce and extreme melancholy. It was found on inquiry, that the man had been bitten by a dog; but he was quite a child at the time, and the dog was a healthy one. He had, however, thought much of this lately; and his fellow-workmen and he had talked much of hydrophobia. It was also found that he had been lately disappointed in love, which had preyed much on his mind. He had been seen on the evening of his seizure to walk in a staggering manner, and subsequently to fall insensible. No evidence was given of his having been drinking. The only treatment in the hospital was a mercurial laxative or two, as his tongue was dirty and his bowels confined. He left in a few days.

Mr. Bulley said that, no doubt, in these two cases, fear was the exciting cause of the attacks of convulsion; the nervous systcm being peculiarly predisposed to receive such an impression, the circulating system became depressed, as indicated by the cold clammy skin, and fecble pulse. 'The internal organs, as it were, became clogged, and the capillaries deserted by the blood; the convulsive movements which ensued were, he thought, a cure for this state of things, by restoring the equilibrium of the circulation. $\mathrm{He}$ leaned to the idea of the first case being really one of tetanus ; but no opium nor other medical treatment having been used to check the salutary spasms, they had thereby opportunity given them to relieve the internal congestion. Mr. Bulley promised on some future occasion to give to the society more fully his ideas on convulsions. I may remark on these two interesting cases, that I thought them to bear a general resemblance to attacks of hysteria, as seen in the female, and also occasionally (though the derivation of the term makes it an awkward one to use) in the male. There were the same causes in operation, which will produce an attack of hysteric convulsion; viz., a state of mental depression and fright. There were the biting and endeavour to injure the hystanders, and the throwing about of the limbs, as if the movements were to a great extent under the command of the will: these symptoms I find mentioned in my account of both cases. There were the same obstinate silence, the apparent insensibility, but real consciousness of what was said and done near them: as witness the abrupt termination of the convulsions, on mention being made of the hospital. The fear of water, I apprehend, in the second case, was due to the one peculiar source of disquietude, i.e., the fear of hydrophobia; the mind having being impressed with the notion, that dread of water was one of the essential symptoms of the disease. The peculiar countenance of tetanus was absent, I think, in the first case, as also the peculiar lasting rigidity of the muscles, especially of the masseters and pterygoids, which, had it been present, would have rendered biting and snapping perfectly impossible. Was the lasting contraction of the flexor muscles of the thumb and forefinger different from the irregular vagaries of muscular action so frequently seen in hysteria?

Disease of the Brain in a Srphimitic Patient: Death. By T. L. Walford, Esq. (June 30th, 1852.) The aubject was a woman, aged 50, who had contracted syphilis four years previously. She had since complained of pain in the head, and was, a day or two sinee, said to have had a fit. She began to turn about restlesely in bed; she could not be got to take medicine; and took little or no food. She answered in monosyllables. There was great difficulty in swallowing. The intelligence was neither exalted nor depressed. The opinion of the Society was in support of the existence of nodes pressing on the brain, and in favour of the use of mercury internally, as well as the application of mercurial ointment to the blistered scalp.

The post mortern examination in this case, as subsequently related by $\mathrm{Mr}$. Walford, revealed opacity of the membranes of the brain, serous effusion at the base, and softening of the right optic thalamus and other central parts.

Mr. MAY mentioned the case of a military man, who had complained of severe fixed pain in the head for a length of time, and he was paralytic; the origin of these symptoms being syphilis. IIe died; and, on pressing upon the painful spot, the bone was found to be destroyed. There would probably have been an ulcer through before long.

Disfase of the pois Varolit. By G. Max, Esq. (Sept. 29th, 1852.) The patient was a girl, Miss C., aged 9. About six months before death, she had fallen from a siving, and had struck the back of her head. In a fortnight, she began to speak badly; then she was sick, especially in the morning; symptoms of chorea followed; she occasionally fell down; etc. At this time, she had convergent squint of the eyes, chietly the right. She gradually lost general power, and was confined to bed for three months before death, having paralysis of the right arm and leg. Both limbs were extended and stiff. The other side became gradually affected, but not to the same extent. Convulsions occurred occasionally; the intelligence, special senses, and sleep, remaining unaffected. She became more asthenic, convulsed, and comatose, and sank by apnoea.

Evermination of the Body. An abscess was found in the right side of the pons Varolii, with ulceration of its entire surface, and congestion of the membranes. The sixth or abducens nerve on the right side was destroyed; the left had also probably been destroyed. There were about four ounces of fluid in the ventricles. This case, Mr. May said, bore out Dr. Marshall Hall's views on the pathology of chorea, as he placed the seat of this disease in the pons Varolii.

DISEASES OF THE RESPIRATORY SYSTEX.

Scdien Deathe in Phthisical Patients. By $T$. $L$. Walfokd, Esq. (May 25th, 1853.) Mr. Walford mentioned that two phthisical patients under his care had died more suddenly than usual; one by bringing up a large quantity of blood; the other, an old man, by syncope.

Mr. MAY said, that the latter was not an unusual termination; the heart, participating in the general debility, being at last unable to carry on the circulation.

Masseg of coagulated Milk in Esophagus of a Chind. By (G. D. Browx, Esq. (May 25th, 18i33.) Some specimens were exhibited by IIr. Brown of what he thought to be cists of the trachea and bronchi; they had been vomited under the use of all emetic, in a child, who had suffered from measles, and had croupy breathing and urgent dyspncea. These symptoms ceased on the action of the emetic. The substinces were white, greasy to the feel, and capable of being rubbed down between the finger and thumb.

Mr. WALrond (and in this the Society coincided) thought these masses were portions of coagulated milk, which had filled the osophangus, and so pressed on the trachea and larynx from hehind.

Mr. Brown was inclined to adopt this opinion, especially as the microscope showed oil-globules. There was no appearance of these masses being tubular; they were quite solid.

DISEASES OF TIE DIGESTIVE STSTEM.

Expulion OF TAPE-Work dNDER THE ACTION OF Kousso. By G. May, Esq. (Oet. 27th, 1852.) Mr. Mry reported a case of expulsion of tape-worm by kousso, fol- 
lowed by crator-oil. The rorm wes subeequently examined microecopically by Mr. Goodwin; but ho did not succeed in finding the head.

Vouturg ayd Exaciation dorrya Przaraxcr. By E. Weurs, M.D. (Jan. 26th, 1853.) The patient was a lady whom Dr. Wells had visited in the Isle of Wight, in June 1852. She was then suffering from vomiting and anorexia. In July, emaciation had rapidly progressed, and tympanitis began. She was placed under the care of a homocopathic practitioner, who five months afterwards suspected pregnancy, and wished her to be removed to London. The uterus was then found to contain an eight months' fœtus. She continued to lose flesh, though taking iced food; and one day she suddenly died, after a hearty meal. When the body was examined, marks of inflammation und ulceration were stated to have been found in the stomach; but there was no other organic disease. The curious points of this case were the obscurity of the signs of pregnancy ; the persistence of emaciation, though abundance of nutriment was taken; and the difference in the character of the vomiting from that of ordinary pregnancy.

The members of the Society thought that the question which presented itself was, Whether, when the existence of pregnancy had been decided on, and was the presumable cause of the romiting, emaciation, etc., premature labour should not have been induced?

Calculi impacted iv the Cystic Duct : Death. By I. Harinson, Esq. (Nov. 23rd, 1852.) Mrs. P., a robust and healthy woman, aged 33 , had been attended by $\mathrm{Mr}$. Harrinson several times, on account of severe bilious attacks, with much pain in the stomach, obstinate vomiting, and slight jaundice. She had married twice, and had become quickly pregnant by her second husband, but had had no children by the first. Seven days before her death, she was seized with vomiting, which continued until within two days of that erent, nothing appearing to arrest it. She had also acute pain in the right hypochondrium. She rapidly became weak; the skin assumed a dirty yellow colour; and her expression became that of hebetude produced by poisoned blood. Delirium supervened, and she sank from asthenia. A blister to the epigastrium, calomel and opium purgatives of tartarised soda, with pills of colocynth and hyoscyamus, constituted the treatment; the diet being beef-tea and brandy, and soda-water with lumps of ice in it. As to the diagnosis, Mr. Harriuson remarked, that it was evident that the under surface of the liver was the part attacked. There was no tumour nor distension of the bowels.

Examination of the Body. The liver was found small, and slightly congested only; its structure being healthy. The gall-bladder was small, with a much thickened capsule; the ducts also were thickened. Two stones, of the size of peas, were impacted firmly in the cystic duct, which was much contracted in calibre. The hepatic and common ducts were pervious. The uterus contained a three months' fœetus.

Mr. Harrinson remarked that there was no obstrcle to the flow of bile from the liver, so that the theory of obstruction to the passage of bile would not apply here. The best explanation he could offer was, that the continued irritation of the impacted calculi so acted on the liver, that its operations became suspended, and the blood, especially in the state of preguancy, became poisoned. Ile thought that poisoned blood was the immediate cause of death.

Obstrection of tue Bowels: Operation for ArtiFicial Anus: Death. By G. May, Esq. (April 20th, 1853.) This case is related in the Assocration Journal, for May 6th, 1853. The points of interest were, the capability of passing a long tube, twenty inches, per rectum; the consequent choosing of the cæcum as the seat of operation, and the revelation, by post mortem examination, of the interesting fact, that the stricture, which was produced by cancerous discase, existed only six inches from the anus, and that a portion of the intestine above falling, as it were, like a valve on the upper opening of the stricture, so perfectly closed it as thoroughly to prevent the freces from coming down, though the tube could readily paes from belor uprand The operation was performed through the anterior abdomi$\mathrm{nal}$ parietes, with the effect of allowing s amall quentity of fæcos to escape before death.

Mr. W ALPORD objected to opening the crecum, both on anatomical and on physiological grounds. The cutting into this part of the bowel, surrounded by peritoneum, involved a greater amount of risk than opening the descending colon from behind. The cæcum, he thought, performed an important part in the function of defrecation; and the colon could not be brought to empty itself here.

Mr. MAY, in reply, stated that the statistics of the oper. tion, as given by Mr. C. Hawkins, did not show a great difference in mortality in favour of the posterior operation; and he (Mr. H.) seemed, in his comments on the cases tabulated by him, rather to prefer the anterior.

Cases of Obstruction of the Bowels: Use of Tobaceo Irjections, By E. H. Payne, Esq. Mr. Payne read the histories of three cases of obstruction of the bowels, in which he had used injections of tobacco. He attributed mueh to this remedy in the recovery of these patients. He had great objection to purgatives when there was obstinate vomiting; and he laid great stress on obtaining good tobacco, recommending highly the sort called Carendish, as being less likely to be adulterated. He infused from twelve to twenty grains of this in a half pint of boiling water, for fifteen minutes.

Case I. James G., aged 68, was seen by Mr. Payne, June 7 th, 1830 , in the evening. This patient had always enjoyed good health, but his bowels had lately been irregular; they had not acted, at the time of his being first seen, for five days $H e$ vomited constantly; the abdomen was distended and uneasy on pressure, and he complained of its being tight; his countenance was anxious; the pulse was 90 and tolerably firm. He was bled to faintness; and calomel and opium with effervescing salines were ordered.

June 8th, morning. The bleeding gave him several hours comfortable sleep; he had no sickness. The vomiting, however, returned about the middle of the day with much pain; the pulse being 108 and weak. Everything was rejected by the stomich. IHe was ordered to have a hot poultice applied to the abdomen; and abstinence from fluids and a continuance in the use of the pills were enjoined.

Evening. The countenance was very anxious; he had vomiting of facal matter; the pulse was 130 ; the abdomen tympanitic; he had constant hiccough. Mr. Payne ordered a tobacco injection ( 3 j. to Oss). It caused slight faintness; the patient had, however, afterwards, some relief from the pain and his sickness abated. He had a wine-glass of pherry during the faintness; and was ordered to continue the pills every three hours. Another injection with fifteen grains of tobacco was used in six hours.

June 9th, morning. He had been sick twice only after the last injection; he had no hiccough; he had expelled some wind by anus. The countenance was improved; the pulse 94 , weak. He was very thirsty. The injection was repeated, and the pills were continued.

E'vening. He was easier; the belly was less tense; he was very thirsty. The injection was repeated; this was followed by free evacuation from the bowels; after which he speedily got well.

CASE II. Mrs. C., a corpulent, drinking woman, was seen by Mr. P., on Feb. 13th, 1832. Her countenance was anxious and sunken; the pulse 111 , very weak; and the abdomen much distended. There was constant romiting of stercoraceous matter, with hiccough; the pain had been very great, but she seemed sinking; her skin was cold and moist. She had been under treatment for a week, for constipation of the bowels. Mr. Payne ordered the following pills to be taken every three hours:

R. Calomelanos gr. ij. Camphoræ gr. Opii gr. i. $\mathbf{M}$.

The patient was directed to abstain from fluid. A tobacco injection ( $\exists$ j. to Oss.) was used. This woman passed some 
flatus on the 15th; and, in the night, a large amount was forcibly expelled, which was followed by an immense fotid evacuation, with some bloody serum. The calomel and opium had been continued, and she had had five more enemata administered, the quantity of tobacco used at a time being from twelve to fifteen grains only, on account of her extreme weakness. Wine and brandy were likewise given. She nearly sank after the evacuation; but, under the use of brandy and opium, with the injection of two drachms of compound tincture of camphor, she gradually recovered, the peritoneal covering of the abdomen being somewhat thickened.

CムsE 1Ir. Mrs. S., a short, stout, thickset washerwoman, was seen by Mr. Payne's assistant on April 2nd, 1838, having then, after a week's constipation, been suddenly seized, at the wash tub, with violent jains in the abdomen. She was bled to six ounces, and croton oil with a senna mixture was ordered; everything was, however, vomited. Afterwards, Mr. Payne himself saw her. The pains were then very violent, and the sickness was excessive; the pulse was 136 , full, and firm. He bled her to twenty-six ounces with much relief to the pain and the vomiting. He ordered two grains of calomel and one of opium every three hours. No fluid was allowed.

On April 3rd, she was again bled to faintness, the sickness and pain being as violent as ever, and fixculent matter being ejected. This woman sank into a very feeble condition.

On April 14th, after a tobacco injection, flatus escaped with a loud noise, which was followed by stools, great faintuess, and produced the flow of bloody serum. She recovered from this faintness under the same treatment as in the previous case; the peritoneum remaining also thickened. She had marked tenderness above the ileum on the left side; two tobacco enemata were administered, the calomel and opium having been continued only up to the $6 \mathrm{th}$, on account of the patient's refusal to take them. She, as well as the second woman, often asked for the injection.

Mr. Payne had been ied to abstain from violent means for getting the bowels open, by having, many years ago, witnessed a case, in which the transverse colon was borne down upon the uterus by the weight of a pound and a half of fluid mercury, the administration of which had formed part of the treatment. IIe determined for the future to have recourse to sedatives, and used the tobacco injection on this account. IIe only allowed a mild aperient after the sickness had subsided. He thought that every addition of fluid in the distended state of the bowels was extremely injurious, and delayed relief.

Scinrhus of tile Pancreas. By G. May, Esq. The tumour had been felt, during life, near the region of the pylorus and towards the umbilicus; it was hard, but not defined; was deep seated, and slightly tender. The prominent symptoms had been, shooting pains through from the abdomen to the back, occusional vomiting, a disgusting taste in the mouth, loathing of food, and flatulent disteusion. The patient died asthenic.

Examination of the Body. The pancreas was found enlarged and nodulated at its head, and infiltrated with scirrhous deposit. Ulecration had commenced in the transverse duodenum posteriorly. The liver contained nodules of scirrho-encephaloid deposit, and one or two existed in the lungs.

Constriction of tile Esopilagus. By R. T. WoonHodse, M.D. (May 25th, 1853.) A lady, aged 43, who had long suffered from dysmenorrhoa, and had some stomach derangements which had generally yielded to alkalies. About eighteen months ago, she complained of pain in swallowing, referred to the lower third of the sternum. Emaciation ensued from the inability to swallow sufficient nourishment, the appetite being craving. She was relieved by anodynes, and partly nourished by asses' milk and injections of becf-tca. The passing of bougies was recommended by a medical friend in London, but another disapproved of this proceeding. She latterly complained of excruciating pain in the mammx, awakening her about one or two o'clock in the morning, notwithstanding large doses of morphia at night. A distinct bruit was heard behind, in the situation of the aorta, between the ninth and twelfth dorsal vertebre. She died on May 20th.

Examination after Death. There was extreme emaciation, but the mammæ were of full size. The csophagus was slightly constricted below the cricoid cartilage; and there was an irregular thickened opening, which led into a small abscess filled with sanious offensive matter. The coats of the tube were infiltrated with a dense greyish deposit, which narrowed the calibre, so as scarcely to admit the finger. About the third or fourth dorsal vertebræ, the tube dilated into a large pouch, containing the same sanious fluid; this sac extended to the right of the spine, and separated the pleura from the root of the lung on this side. Just above the cardiac orifice of the stomach, there was a dense ring of adventitious deposit, about half an inch in thickness, through which, however, the finger passed readily into the stomach. The large pouch presented internally a number of nodulations, irregular in shape. The stomach was slightly congested; the pylorus was healthy. A lymphatic gland at the head of the pancreas presented some malignant deposit. 'The cervix uteri was hypertrophied, and the os contracted. There was a hard calcareous mass, as large as a pullet's egg, at the situation of a bronchucele which had been cured by iodine.

This case showed the value of beef-tea injections in sustaining life for a long period; the patient having been mainly supported by this means for twelve months. The pain in the mammx Dr. Woodhouse explained by the pressure of the thoracic abscess on the intercostal nerves.

The following cuse illustrates the necessity of extreme caution in the use of bougies. A man had dysphagia, hoarseness, cough, and hamoptysis, but only to a moderate amount. After some time, an aneurism was diagnosed, on account of dulness under the upper part of the sternum, and to the right of it, with impulse, and an occasional indistinct bruit. The man died; and a small aneurism was seen, which opened into the left bronchus, and also into the œsophagus, by large apertures with rounded edges, showing that they had existed some time. The free flow of blood had apparently been prevented by clots blocking up the apertures. 'The opening into the osophagus would have readily admitted the end of a bougic. Mr. May has reported a similar case. On the other hand, in cases of apparent obstruction of the osophagus, the passing of bougies has nat only been not detrimental, but has afforded the greatest relief.

The value of beef-tea injections is further shown in the case of a child, who had been burnt on the shoulder. This burn was followed by erysipelas of the whole trunk; he had diarrhœea, and obstinate vomiting of everything given; the ejecta being like coffee-grounds. The features were sunk, and the pulse was almost imperceptible. He appeared, in fact, to be sinking. A beef-tea injection, containing two drops of laudanum, was ordered to be given every four hours; and collodion was painted frecly over the reddened skin. The vomiting and diarrhoca ceased as if by magic; and, after a few injections, the child was able to take nou rishment by the mouth, and recovered from its perilous condition.

Reading, Septcmber $18: 3$.

\section{[To be continued. $]$}

\section{ON CHANGE OF SIGHT AS PREMONITORY OF HARD CATARACT.}

By W. WHITE COOl'ER, F.R.C.S., Ophthalmic Surgeon to St. Mary's Hospital, and Senior Surgeon to the North London Eye Infirmary.

Is the second edition of my work On Near Sight, Aged Sight, etc., reference is made to a class of cases of raro occurrence-cases in which persons, having been presbyopic, and having used convex glasses, as they advance in years recover natural vision, or become near-sighted. I 